\title{
University of Bohol Employees Work Engagement: Measuring Workplace Productivity
}

\author{
MARILOU V. FUDALAN \\ mvfudalan@universityofbohol.edu.ph \\ https://orcid.org/0000-0002-7535-7413 \\ EMMANUEL ROD V. FUDALAN \\ ervfudalan@universityofbohol,edu.ph \\ https://orcid.org/0000-0003-2070-2942
}

\begin{abstract}
Theories on work engagement posited that engaged employees are physically, cognitively, and emotionally driven to attain the organizational goals. Thus, they produce high levels of workplace productivity. Workplace productivity indexes serve as a parameter that measures how satisfactorily employees are doing and what motivates them to achieve higher goals and higher levels of efficiency and effectiveness. This study aimed to determine the level of work engagement of the human capital of the university as measured by workplace productivity. A quantitative-descriptive method with the use of the Workplace Productivity Snapshot Tool was utilized in the conduct of the research. The data collected were analyzed and interpreted using simple percentage, weighted mean, one-way Analysis of Variance. Results showed that the UB employees were highly productive in building leadership and management capability, organizing work, networking, and collaboration and measuring what matters. However, they are moderately productive in creating productive workplace cultures, encouraging innovation, and the use of technology and investing in people and skills. Workplace Productive Snapshot Tool yielded moderately productive as those needing continuing feedback, monitoring, and evaluation to keep up with individual and environmental challenges. Based on the salient
\end{abstract}


findings, it is elemental to determine the learning and development needs. Such will enable the employee to improve performance and achieve higher workplace productivity continually.

Keywords: Human resource management, work engagement, workplace productivity, Analysis of variance - one way, Tagbilaran City, Bohol, Philippines.

\section{INTRODUCTION}

Work occupies a significant fraction of our day to day existence. At a particular facet of our lives, we all have to work and make a decent living. Once we commence working, the possibility is that we will be spending almost all the remaining years of our lives at work. For over decades now, human resource management (HRM) has engrossed its strategies on sustaining the highest level of work engagement among employees in all ranks and the nature of work. Employee engagement is a broad concept that affects practically all components of human resource management facets we recognize. It is broadly explained by experts as an active connection of employees to a positive, fulfilling, work-related state of mind that is characterized by vigor, dedication, and productivity (Schaufeli, \& Salanova, 2011). Bakker, (2010), the father of work engagement researches, characterized it as an affective-motivational optimistic condition of work-related happiness that can be seen as the antipode of job burnout. In his evidenced-based model of work engagement, employees who are engaged in their work are known to be productive, innovative, open-minded, pro-active, and are extra-milers (Bakker, 2011).

Work engagement is considered to be a two-way relationship between employer and employee. Engaged workers have conscious awareness of the institution's business framework and work with colleagues to increase productivity on the job at the advantage of the organization. On the other hand, the administrators work on developing and nurturing engagement to provide a roadmap for fully engaged employees on the job (Kompaso, \& Sridevi, 2010). A need to conduct training assessment to develop training programs that meet the needs of the human resource. Hence, employees will be fully engaged.

Studies showed the connection between employee engagement and organizational performance outcomes. Those two increase employee 
productivity. Further, such connection increases the probability that the employer can surpass the average industry profits (Kompaso \& Sridevi, 2010). In this study, it stated that engaged employees continuously shows three general SSS behaviors which can either increase and decrease workplace productivity.

The concept of work engagement is rather new in the field of human resource management and emerged in the kinds of literature for nearly two decades ago. Kahn (1990) was one of the forerunners of theories concerning work engagement. He held that engaged employees are physically, cognitively, and emotionally driven towards attaining organizational goals, thus producing high levels of workplace productivity (Bakker, 2011).

However, quantifying workplace productivity is a complicated procedure. There are fundamental questions that need to be answered like, what does it mean to have a productive workplace? Is productivity measured strictly by financial results or do other characteristics play a role in the final definition ascribed by organizational leaders?

It is then that measuring workplace productivity becomes imperative in all organizations to have a strong perspective with regards to organizational results, processes, and outcomes. Workplace productivity indexes serve as a parameter that measures how satisfactorily employees are doing and what motivates them to achieve higher goals and higher levels of efficiency and effectiveness (Van der Voordt, \& Riratanaphong, 2014). Results of the assessment done can be employed as an essential tool for managers to answer strategically critical questions like where have we been; where are we now; where do we want to go; how are we going to get there; and how will we know that we got there (Van der Voordt, \& Riratanaphong, 2014).

Over the past decade, many measures have been done to improve the educational system to ensure that all students have an effective teacher in the classroom. The segment of the academe is among the few industries for which worker productivity measures are accessible for a considerable portion of the workforce. A large number of researches concluded that teachers are more productive at the beginning of their careers this is so because of the availability of effective mentors, regularity in teaching assignments, and encouraging work environment. However, across the years, there is a decline in productivity. As observed, experienced teachers can only improve their instructional effectiveness upon participation in the rigors of the teacher evaluation program. Besides, they should find more 
partner organizations, institutions, and companies to engage effective onthe-job training (Papay \& Kraft, 2015).

On the other hand, of workers' job satisfaction and workplace productivity are two of the chief factors contributing to the capability and competitiveness of most institutions (Lottrup, Stigsdotter, Meilby, \& Claudi, 2015). In a study on most common causes on how to improve office workers' productivity, results showed the conducive physical working environment, workers' collaborative spirit, open communication, job satisfaction and dedication to the organization, and opportunity for rest and recreation (Lottrup et al., 2015). Enhancement of the workplace and on the intensity to which workers can influence the office organization is necessary concerning organizational identification, well-being, and productivity (Knight \& Haslam, 2010).

One theory that is in agreement to valuable workplace productivity is organizational support theory. According to this theory, reciprocity norm suggests that employees who observed that their organization offers them with a high level of support, feel morally obligated to work more for the organization (Alfes, Shantz, Truss, \& Soane, 2013). Perceived organizational support (POS) has a beneficial effect on employee's attitudes and behaviors. This support leads to an increase in their levels of work engagement and organizational citizenship behavior and lower levels of turnover intentions. According to Neves and Eisenberger, (2014), POS is manifested in employees who enjoy salary increments and those sent to training and seminars. They also feel the necessity to repay the organization by accomplishing its objectives.

Frederick Herzberg's Two-Factor Theory explains that two opposing sets of factors influence job satisfaction and dissatisfaction. These factors are job content as motivators and job context as a hygiene factor that cannot be evaluated on the same continuum (Stello, 2011). Experts said that work satisfaction increases work productivity (Suojanen. 2012). Tan, \& Waheed, (2011) said motivators include factors that are intrinsic to the job, such as achievement, recognition, responsibility, and advancement while hygiene factors are extrinsic to the job, such as interpersonal relations, salary, supervision, and company policy. When hygiene factors are absent, it produces dissatisfaction at the workplace, whereas motivators create satisfaction and lead to peak levels of motivation, thereby increasing workplace productivity (Dartey-Baah, \& Amoako, 2011). Further, Motivational-Hygiene Model states that the attainment of 
employee motivation happens when workers are placed on a challenging but enjoyable work environment. In such a situation, one can achieve, grow, and show a sense of responsibility, and eventually progress in the organization. Besides, the employees' efforts are recognized, thereby bringing job satisfaction and motivation. A right combination of hygiene and motivator factors can lead to an ideal employee, and such are attainable with the combination of high hygiene and high motivation. They are highly motivated and have few objections. Those with high hygiene and low motivation will lead to a poorly motivated employee and have few complaints. Those with low hygiene and high motivation will create a motivated employee with plenty of complaints.

Herzberg explained further that it does not take only the motivator factors to motivate employees. Neither does it take the hygiene factors to eliminate dissatisfaction. However, motivate and satisfy employees, managers necessitate to effectively combine the factors to appropriately match the specific needs of the employees (Dartey-Baah \& Amoako, 2011).

For this particular study measuring workplace productivity encompasses seven identified drivers from Workplace productivity Snapshot Tool that can make the workplace more productive, satisfying, and engaging. Firstly, it covers building leadership and management capability of employees. Those include activities like cultivating leadership skills at every rank of the organization, managing by example, making an optimistic and productive work environment. Further, it ensured that the staff has the skills and resources advancement and achievement. It capitalizes on management development and training and supporting innovative and creative thinking. The study further discussed that effective leadership is about having a clear vision of where the organization is going and at the same time, motivating the human capital to pursue greater heights. The second driver emphasized on the creation of productive workplace cultures. It can be done through sound management of human capital at all ranks. It made sure that workforce shares the same vision-mission-goals. All employees are allowed to propose improvements for their part of the organization. A supportive relationship between staff, teams, and managers are a good indicator of a productive workplace. A positive work environment motivates people and helps them commit to the organization and helps them extend for the extra mile. It is also important to place value on human resource ideas and experience. Their ideas can help the workplace to do 
things much smarter and better, making the organization more creative and productive. The third driver is the process of encouraging innovation and the utilization of technology. Such include aspects of looking out for new technologies that would be more useful to the organization, regularly engaging in research and development, requiring employee needs assessment on training when new technology is available. Further, it can be done by being open to innovation and providing a platform to give new ideas or processes. Innovation plays an important role in raising workplace productivity. To employ more highly-skilled and highly-paid workers, and through innovation, the organization increases its profitability and prestige. Fourthly, workplace productivity involves investing in people and skills. Literature has written that the more skilled the staff is, the more creative they can be. Training leads to higher levels of work engagement leading to fewer stresses and burnout. Skilled workers have lesser room for mistakes, and necessitate less supervision, takes on more responsibility, and are better correspondents. Investing in people and skills include the process of providing appropriate training to be effective, offering all employees with chances for formal education, forming mentoring and coaching networks within the organization. Furthermore, it extends to assessing the skill level of employees, ensuring that high levels of literacy, expertise, and computer skills are sustained and arranging staffs personal career development plans. The fifth driver is on organizing work which entails incorporating the following factors: (a) ensuring that employees understand their role in achieving organizational goals; (b) acknowledging and rewarding individuals whose works support organizational goals; (c) regularly evaluate work developments and workflows; (d) urging staff to suggest about how the workplace can better operate; and (e) regularly communicating valuable information across departments, processes and networks. Productive workplaces have assemblies and processes that allow them to adjust and develop as products, technology, and industry needs change. A well-organized workplace can obtain the best out of its staff and technology. Workplace productivity driver six is on networking and collaboration which emphasized on building relationships with other likeminded institutions and industry partners; linkage with regional or national industry organizations; establishing good business relationships with clients and other organizations; and becoming involved in local, regional or national government agencies programs. Workplace productivity can be surely enhanced by exchanging concepts, ideas, and best practices 
with other like-minded industry. Collaboration is a tool that can decrease financial cost and open an avenue to access to new resources. The last driver talks about measuring what matters which can be achieved by ensuring that management information systems provide the correct information needed to know how well the business is doing; measuring performance against institutional goals rather than just focusing on financial performance; identifying key result indicators and regularly evaluating them throughout the year; making sure that all employees know the key performance indicators; assessing customer satisfaction, employee morale and supplier feedback; and benchmarking the institution against industry best practices. It is imperative to measure the worth of all the investments place to improve workplace productivity, and at the same time, it sets a tone on the next target to accomplish not only in the organizational structure but on the human resource and the market as well.

This study aimed to determine the level of work engagement of the human capital of the university as measured by workplace productivity. The thought-provoking outcomes will operate as a commendable resource for broadening strategic development planning of human resources.

Specifically, it seeks out to respond to the following inquiries namely:

1. What is the profile of the respondents in terms of:

1.1. age;

1.2. sex;

1.3. nature of work;

1.4. status of employment; and

1.5. educational attainment?

2. What is the workplace productivity of the human capital as to the nature of work in the following drivers:

2.1. building leadership and management capability;

2.2. creating productive workplace cultures;

2.3. encouraging innovation and the use of technology;

2.4. investing in people and skills;

2.5. organizing work;

2.6. networking and collaboration; and

2.7. measuring what matters?

3. Is there a significant degree of variance in the different workplace productivity drivers? 
4. What valuable recommendations could be proposed from the formulated conclusions?

\section{METHODOLOGY}

A quantitative descriptive design with the aid of a standardized tool was used in pursuit of the research objectives. Results relied on individuals' self-reports for all variables which raised the concern of possible common method bias. However, the statistical analysis shows that common method bias did not cause significant concern in the study. Moreover, the focus of the research was on employees' perception of workplace productivity. The self-report measure is the most valid measurement method for the variables, as individuals are best to report their levels of productivity.

The study was conducted in the different academic and non-academic departments and campuses of the University of Bohol. The university manages three campuses, such as University of Bohol (UB) - Main Campus along Maria Clara Street, University Grade School (UGS) along the same street and UB-Victoriano D. Tirol, Sr. - Advanced Learning Center (UB-VDT-ALC) along Penaflor St. Taloto District Tagbilaran City, Bohol. There are two basic education courses, namely elementary education in UGS and VDT- ALC and university high school (UHS) in UB-Main Campus and UB-VDT-ALC respectively.

There were five executive offices, namely Presidentıs Office, VicePresident for Administration office, Vice President for Academics Office and Finance Office. The academic departments comprises fourteen divisions in UB-Main Campus namely College of Physical Therapy and Occupational Therapy (CPTOT), College of Criminology (COC), College of Architecture and Fine Arts (CAFA), College of Business and Accountancy (CBA), College of Pharmacy (COP), College of Hotel Restaurant Management Tourism and Nutrition (CHMTN), College of Nursing (CON), College of Midwifery, College of Engineering and Technology (CET), Teachers College (TC), College of Arts and Sciences (CAS), Graduate School and Professional Studies (GSPS).

This particular study included all executive council, academic personnel, and non-academic personnel. Those have the status of fulltime regular, full-time probationary, part-time, contractual, and professorial. Respondents on probationary status included those who have served the university for at least one year. 
Table 1 illustrates the distribution of the respondents with the teaching personnel comprising most of the bulk of the respondents. Questionnaires distributed were 280 , and those who participated in about $59.28 \%$ of the targeted respondents.

Table 1. Distribution of Respondents

$\mathrm{N}=166$

\begin{tabular}{lccc}
\hline \multicolumn{1}{c}{ Respondents } & Frequency & $\%$ & Rank \\
\hline Administration & 27 & 16.26 & 2 \\
Teaching & 113 & 68.07 & 1 \\
Non-Teaching & 12 & 7.23 & 4 \\
Support Services & 14 & 8.43 & 3 \\
$\quad$ TOTAL & 166 & $100 \%$ & \\
\hline
\end{tabular}

The Workplace Productivity Snapshot Tool described how efficiently the business is managed and how well it uses its staff and resources. It also looked into the organization of the workplace. Further, it assessed how the workplace culture impacts on the overall productivity of the business. The crafting of the tool was on December 2003 by the New Zealand Cabinet Business Committee of the Workplace Productivity Working Group (WPWG). Results advised the Government on practical ways to improve New Zealand's productivity performance. The International Marketing \& Social Research used this tool in June 2005 in conducting a series of quantitative research studies with both employers and employees in relation to practices implemented to improve workplace productivity and work-life balance, respectively. Scoring includes 1.00-1.74 is unproductive, 1.7-2.49 is somewhat productive, $2.50-3.24$ is moderately productive, and $3.25-4.00$ is productive.

Data for this research were collected through a standardized questionnaire, but before data collection commences, permission was requested from the University's human resource manager and vicepresident for administration. Upon securing the consent, the distribution of the questionnaires transpired. During the distribution process, the purpose of the study was fully explained, verbally. Although participation was encouraged, the respondents were informed that participation is voluntary, and anyone could withdraw at any stage if they feel the need to discontinue. 
This study took note of ethical considerations. Permission to conduct the research is to be requested from the University's Ethics Committee. The respondents' consent to participate in the research voluntarily were secured. The gathered data were dealt with the utmost confidentiality.

The data collected for a socio-demographic profile and workplace productivity level were analyzed and interpreted using simple percentage and weighted mean. Analysis of variance - one way was used to analyze the significant degree of variance on the workplace productivity level.

\section{RESULTS AND DISCUSSION}

\section{Profile of the Respondents}

As indicated in Table 2, the demographic profile of survey respondents showed that they are typically females, most of them are 20 years old and more, the majority of them are teachers, and are full-time regular employees.

\section{Table 2. Profile of Respondents}

\begin{tabular}{lccc}
\hline \multicolumn{1}{c}{ Items } & $\mathrm{F}$ & $\%$ & $\mathrm{R}$ \\
\hline Age (years) & & & \\
$20-40$ & 90 & 54.22 & 1 \\
$41-60$ & 68 & 40.96 & 2 \\
$\quad 81$ and above & 8 & 4.82 & 3 \\
Sex & & & 2 \\
$\quad$ Male & 64 & 38.55 & 1 \\
$\quad$ Female & 102 & 61.45 & 3 \\
Highest Educational Attainment & & & 2 \\
$\quad$ Doctoral & 19 & 11.45 & 1 \\
$\quad$ Masteral & 61 & 36.75 & 4 \\
$\quad$ Baccalaureate & 83 & 50.00 & 5 \\
$\quad$ Associate & 2 & 1.20 & 2 \\
$\quad$ Technical-Vocational & 1 & 0.60 & 4 \\
Nature of Work & & & \\
Administrator & 27 & 16.27 & 7.23 \\
Non-teaching & 12 &
\end{tabular}




\begin{tabular}{lccc}
\hline Support Services & 14 & 8.43 & 3 \\
Teaching & 113 & 68.07 & 1 \\
Status of Employment & & & \\
Contractual & 9 & 5.42 & 3 \\
Full-time regular & 117 & 70.48 & 1 \\
Part-timer & 7 & 4.22 & 4 \\
Probationary & 33 & 19.88 & 2 \\
\hline
\end{tabular}

Workplace Productivity of UB employees. Table 3 shows the result of the evaluation and assessment done on the workplace productivity index of the employees in the different departments. The overall workplace productivity score of the university is 3.28 , which means that the respondents are highly productive. On the specific drivers, the results are as follows.

\section{Administrators}

Building Leadership and Management Capability. This driver measured effective leadership as about everyone having a clear vision of where an organization is heading. It's about identifying new opportunities and inspiring people and the teams they work in to pursue those opportunities. The overall rating for administrator is 3.47 which is highly productive on the following measures namely, workplace encourage leadership at every level of the organization (3.52); organization do succession planning for all jobs, so there are clear career paths for the staff (3.48); managers lead by example and create a positive and productive work environment (3.37); organization invest in development and training for its managers (3.48); and the workplace support innovative thinking and make use of new ideas (3.48).

Creating Productive Workplace Cultures. The respondents on this driver are graded as 3.39 , which is highly productive. Ratings on the different measures are as follows: staff share the same goals and values (3.48); people in the workplace treat each other well and value each other's ideas (3.37); everyone in the organization gets the chance to suggest how they could improve their part of the business (3.44); organization reward people for participating and suggesting good ideas (3.33); and workplace gather feedback from staff on the work environment and any ideas staff have for improving it (3.33). 
Encouraging Innovation and the Use of Technology. Innovation is the key to raising workplace productivity. The group is rated 3.39 or highly productive. The following measures assessed are pertaining to research and the development of new ideas. It includes the following, products and services (3.70); staff asked about what new technology could be useful to introduce into the organization (3.41); staff received training when new technology is introduced (3.37); and opportunities for staff to suggest new ideas or processes (3.37). However, the workplace is moderately productive in opening up to new ideas and in doing things differently (3.11).

Investing in People and Skills. The more skills staff have, the more innovative they can be, and the more they can contribute. On this driver, the respondents rating is 3.37 , which is highly productive. Specific scores for each measure are opportunities in the workplace for all staff to have formal learning like industry qualifications; job specific training (3.48), staff has good reading, writing, mathematics and computing skills (3.48); staff have personal career development discussions or plans (3.37); opportunities in the workplace for experienced employees to support/coach/mentor less experienced staff (3.26); and staff receive the training they need to be effective (3.26).

Organizing Work. A well-organized workplace can get the best out of its staff and technology. It values everyone's contribution and encourages people to share information and ideas. Productive workplaces have structures and processes that enable them to adapt and grow as products, technology, and markets change. Overall rating of the group is 3.49, which is highly productive. Individual scores per measure are as follows: staff understand their role in helping the organization achieve its goals (3.78); organization encourage staff to suggest ways to improve the products, services or the way we work (3.48); workplace recognize and reward people whose efforts support the firm's goals (3.44); workplace regularly analyze work processes and work flows (3.37); and staff regularly share information between teams and work areas (3.37).

Networking and Collaboration. Workplace productivity can also be improved by exchanging ideas and information with others in the industry. Respondents are graded 3.48, which is highly productive. Scores for each measure are organization has a good relationship with the community (3.74); organization has a good relationship with its students/ clients/employees (3.70); organization well linked to other people and organizations in the industry or sector both local or national organizations 
(3.44); and organization is connected with any local, regional or national government agencies or program (3.37). However, the administrator group rated moderately productive in organization explored opportunities for working with or entering into joint ventures with others (3.15).

Measuring What Matters. It is essential to assess the value of any investment in an organization makes in improving its workplace productivity. Keeping track of this will help the organization find out the things that are shaping the most significant difference. The total rating on this driver is highly productive (3.40). Specific ratings on highly productive items included organization able to collect the information it needs, to assess how well it is doing (3.56); organization measure or monitor customer satisfaction, employee morale and supplier feedback (3.48); organization benchmark operation against industry best practice (3.44); organization regularly measure a range of key performance measures/indicators that go beyond just financial performance (3.26); and everyone knows what the organization ss key performance measures are (3.26).

\section{Non-teaching Personnel}

Building Leadership and Management Capability. Respondents in this group are rated highly productive (3.53). Items that are rated as highly productive are workplace encourage leadership at every level of the organization (3.67); organization invest in development and training for its manager (3.58); workplace support innovative thinking and make use of new ideas (3.58); organization do succession planning for all jobs, so there are clear career paths for staff (3.42); and managers lead by example and create a positive and productive work environment (3.42).

Creating Productive Workplace Cultures. Respondents in this group are graded as highly productive on this driver (3.68). The items that were grossly graded as highly productive includes everyone in the organization gets the chance to suggest how they could improve their part of the business (3.92.); staff share the same goals and values (3.83); people in the workplace treat each other well and value each other's ideas (3.75); workplace gather feedback from staff on the work environment and any ideas staff have for improving it (3.58); and organization reward people for participating and suggesting good ideas (3.33).

Encouraging Innovation and the Use of Technology. Respondents are grossly graded 3.63 on this driver which was highly productive. It included the following items which were rated as highly productive 
namely, staff receive training when new technology is introduced (3.75); opportunities for staff to suggest new ideas or processes (3.75); workplace open to new ideas and doing things differently (3.67); organization invest in research and the development of new ideas, products or services (3.50); and staff asked about what new technology could be useful to introduce into the organization (3.50).

Investing in People and Skills. Overall score on this driver is 3.73 , which is highly productive. Items which are rated as highly productive included opportunities in the workplace for experienced employees to support/coach/mentor less experienced staff (3.83); opportunities in the workplace for all staff to have formal learning like Industry qualifications, job specific training (3.75); staff has good reading, writing, mathematics, and computing skills (3.75); staff receive the training they need to be effective (3.67); and staff have personal career development discussions or plans (3.67).

Organizing Work. This group has an overall rating of 3.70, which was highly productive. The scores for each item are staff understands role in helping the organization achieve its goals (4.00); organization encourage staff to suggest ways to improve the products, services or the way we work (3.75); staff regularly share information between teams and work areas (3.67); workplace regularly analyze work processes and work flows (3.58); and workplace recognize and reward people whose efforts support the firm's goals (3.50).

Networking and Collaboration. On this specific driver, the respondents were highly productive as well, with a rating of 3.75. Each item are also rated highly productive comprising organization has a good relationship with the community (3.83); organization has a good relationship with its students/clients/employees (3.83); organization well linked to other people and organizations in the industry or sector (3.75); organization explored opportunities for working with or entering into joint ventures with others (3.67); and organization connected with any local, regional or national government agencies or program (3.67).

Measuring What Matters. Respondents on this group are rated 3.47 which is highly productive. For each specific item they are also rated highly productive which includes organization regularly measure a range of key performance measures/indicators that go beyond just financial performance (3.58); organization able to collect the information it needs, to assess how well it is doing (3.50); organization benchmark 
operation against industry best practice (3.50); everyone know what the organization's key performance measures are (3.42); and organization measure or monitor customer satisfaction, employee morale and supplier feedback (3.33).

\section{Support Services}

Building Leadership and Management Capability. The respondents in this group are rated as highly productive (3.30) on this driver. Items which were rated as highly productive are as follows: organization invest in development and training for its managers (3.36); workplace encourage leadership at every level of the organization (3.39); organization do succession planning for all jobs, so there are clear career paths for staff (3.39); managers lead by example and create a positive and productive work environment (3.39); and workplace support innovative thinking and make use of new ideas (3.39).

Creating Productive Workplace Cultures. For this specific driver, the respondents are graded moderately productive (3.10). There is one item only that was rated highly productive, which is staff share the same goals and values (3.43). Items rated as moderately productive included everyone in the organization gets the chance to suggest how they could improve their part of the business (3.14); people in the workplace treat each other well and value each other's ideas (3.14); workplace gather feedback from staff on the work environment and any ideas staff have for improving it (2.93); and organization reward people for participating and suggesting good ideas (2.86).

Encouraging Innovation and the Use of Technology. The overall rating for this specific driver is 3.29 , which is highly productive. Items rated as highly productive includes organization invest in research and the development of new ideas, products or services (3.50); staff receive training when new technology is introduced (3.29); and workplace open to new ideas and doing things differently (3.29). However, they are moderately productive on staff asked about what new technology could be useful to introduce into the organization (3.21); and opportunities for staff to suggest new ideas or processes (3.14).

Investing in People and Skills. Respondents comprising this group are rated as moderately productive (3.13). There is only one item that is graded as highly productive, which is the staff has good reading, writing, mathematics, and computing skills (3.36). The rest of the items are rated as 
moderately productive which are the following: staff have personal career development discussions or plans (3.14); staff receive the training they need to be effective (3.07); opportunities in the workplace for experienced employees to support/coach/mentor less experienced staff (3.07); and opportunities in the workplace for all staff to have formal learning like Industry qualifications, job specific training (3.00).

Organizing Work. This driver is also rated as moderately productive (3.24) which consist of staff regularly share information between teams and work areas (3.07) and workplace recognize and reward people whose efforts support the firm's goals (2.86). There are also items that are rated as highly productive which includes staff understand your role in helping the organization achieve its goals (3.71); workplace regularly analyze work processes and work flows (3.29); and organization encourage staff to suggest ways to improve the products, services or the way we work (3.29).

Networking and Collaboration. Respondents on this driver are graded as 3.56, which is highly productive. Items graded as such includes organization has a good relationship with the community (3.79), organization has a good relationship with its students/clients/employees (3.71); connected with any local, regional or national government agencies or program (3.64); organization explored opportunities for working with or entering into joint ventures with others (3.36); and organization well linked to other people and organizations in the industry or sector (3.29).

Measuring What Matters. Computed rating for this group is 3.46 , which is highly productive. Items rated as highly productive are organization able to collect the information it needs, to assess how well it is doing (3.57); organization measure or monitor customer satisfaction, employee morale and supplier feedback (3.50); everyone knows what the organization's key performance measures are (3.43); organization benchmark operation against industry best practice (3.43); and organization regularly measure a range of key performance measures/indicators that go beyond just financial performance (3.36).

\section{Teaching Personnel}

Building Leadership and Management Capability. Respondents in this group are graded as moderately productive (3.17). Items that have a moderately productive rating included workplace support innovative thinking and make use of new ideas (3.21); managers lead by example and create a positive and productive work environment (3.16); organization 
invest in development and training for its managers (3.12); and organization do succession planning for all jobs, so there are clear career paths for staff (3.09). There is only one item that is rated highly productive, which is workplace encourage leadership at every level of the organization (3.29).

Creating Productive Workplace Cultures. This driver is rated as moderately productive (3.16). Specific rating for this item includes everyone in the organization gets the chance to suggest how he/she could improve their part of the business (3.18); workplace gather feedback from staff on the work environment and any ideas staff have for improving it (3.12); and organization reward people for participating and suggesting good ideas (2.94). There are also items on this driver that are rated as highly productive and these included people in the workplace treat each other well and value each other's ideas (3.27), and staff share the same goals and values (3.27).

Encouraging Innovation and the Use of Technology. The overall rating for this driver is 3.14 , which is moderately productive. Items with moderately productive rating includes staff asked about what new technology could be useful to introduce into the organization (3.13); staff receive training when new technology is introduced (3.10); workplace is open to new ideas and doing things differently (3.10); and opportunities for staff to suggest new ideas or processes (3.10). However there was one item which is rated as highly productive which is organization invest in research and the development of new ideas, products, or services (3.29).

Investing in People and Skills. Computed rating for this driver on this group of respondents is 3.16 , which is moderately productive. Items rated as moderately productive includes staff receive the training they need to be effective (3.16); opportunities in the workplace for experienced employees to support/coach/mentor less experienced staff (3.14); staff have personal career development discussions or plans (3.12); and opportunities in the workplace for all staff to have formal learning like industry qualifications and job specific training (3.11). However, one item was rated as highly productive, which is the staff has good reading, writing, mathematics, and computing skills (3.27).

Organizing Work. Respondents on this driver are rated as moderately productive (3.29). Items which are rated as such included workplace recognize and reward people whose efforts support the firm's goals (3.23); organization encourage staff to suggest ways to improve the products; services or the way we work (3.23); workplace regularly analyze work 
processes and work flows (3.19); and staff regularly share information between teams and work areas (3.19). One item is rated as highly productive, which is staff understand their role in helping the organization achieve its goals (3.58).

Networking and Collaboration. The overall rating for this driver is 3.32 which is highly productive, and this included items on organization have a good relationship with the community (3.47), and the organization has a good relationship with its students/clients/employees (3.47). However, there were items that were rated as moderately productive which were organization connected with any local, regional or national government agencies or program (3.25); organization well linked to other people and organizations in the industry or sector (3.25); and organization explored opportunities for working with or entering into joint ventures with others (3.15).

Measuring what Matters. Respondents on this driver are rated as 3.19 or moderately productive. This rating included items on organization regularly measure a range of key performance measures/indicators that go beyond just financial performance (3.21); organization benchmark operation against industry best practice (3.21); organization measure or monitor customer satisfaction, employee morale and supplier feedback (3.19); and everyone know what the organization's key performance measures are (3.04). And one item only is rated highly productive, which is the organization can collect the information it needs, to assess how well it is doing (3.31).

Overall Workplace Productivity Profile of the UB Employees. The overall workplace productivity score of the university is 3.28 , which means that the respondents are highly productive.

Building Leadership and Management Capability. The overall score on this driver is highly productive (3.26). With regards to its specific score per item, respondents are highly productive in encouraging leadership at every level of the organization (3.34) and support innovative thinking and make use of new ideas (3.29). However, respondents are moderately productive on investing development and training for its managers (3.23); managers lead by example and create a positive and productive work environment (3.22), and the organization does succession planning for all jobs, so there are clear career paths for staff (3.19).

A transformational leadership style refers to the leader's behavior such as individual sensitivity, inspirational motivation, and intellectual 
reinforcement that alters employees' standards and values, and encourages them to accomplish organizational goals that go past their personal interests (Bakker, 2017). The study further stated that leaders who inspire their subordinates and provide individual attention to them shape trust and produce a positive team environment. Recent research of Bakker (2017) has also shown that transformational leadership and a high-quality relationship between leader and subordinates can influence followers' job characteristics, and in this way have an indirect influence on employee attitudes, performance, and psychological health.

Creating Productive Workplace Cultures. On this driver, the university had an overall score of 3.23 , which means moderately productive. On specific score per item, respondents are highly productive on staff sharing the same goals and values (3.36); people in the workplace treat each other well and value each other's ideas (3.31); and everyone in the organization gets the chance to suggest how they could improve their part of the business (3.27). Respondents are moderately productive on workplace gathering feedback from staff on the work environment, and any ideas staff have for improving it (3.17); and organization reward people for participating and suggesting good ideas (3.02).

According to Masa' deh, Almajali, Alrowwad, \& Obeidat (2019), organizational culture is one of the most significant organizational level precursors for job satisfaction and productivity. Culture forms a mutual way of thinking and understanding that motivates how employees understand organizational goals and in turn, influences employees' attitudes and behaviors (Bellou, 2010). Bellou's findings proposed that employees identify certain cultural traits as job contentment amplifiers which will lead to higher workplace productivity which includes fairness, opportunities for personal growth, enthusiasm for the job, and good reputation.

Encouraging Innovation and the Use of Technology. The overall score of the respondents is 3.23 , which has a descriptor of moderately productive. For each specific item, respondents are highly productive on the organization investing in research and the development of new ideas, products, or services (3.39). They are moderately productive on staff asked about what new technology could be useful to introduce into the organization (3.21); staff receiving training when new technology is introduced (3.20); opportunities for staff to suggest new ideas or processes (3.19) and workplace open to new ideas and doing things differently (3.16). 
Technology contributes to the efficiency of the employees in the organization with regards to speed, reduction of waste and loss of human capital, material and financial resources Ahmed, Abu-Naser, El Talla, \& Al Shobaki, (2018). Thus, it is well-defined that advanced technology will achieve the regulatory environment capable of eliminating the feeling of monotony and routine in performance, and the self-innovations of the individual and groups at work, and achieve the organizational climate suitable for outstanding workplace productivity.

Investing in People and Skills. The total score on this domain is 3.23 , which is moderately productive. They are highly productive on one item, which is the staff has good reading, writing, mathematics, and computing skills (3.35). They are moderately productive on staff receive the training they need to be effective (3.20); opportunities in the workplace for all staff to have formal learning (3.20); opportunities in the workplace for experienced employees to support/coach/mentor less experienced staff (3.20); and staff have personal career development discussions or plans (3.20).

To attain a high work performance culture, an institution must give its employees training and development programs designed specifically to instill, build and change attitudes and/or behaviors towards numerous organizational functions (Ibrahim, Boerhannoeddin, \& Bakare, 2017). Facts in the study affirmed that training is one of the keys that allow organizations to achieve a high work performance, it is essential to identify the kind of training and development program that the organization needs in order to change the culture, that is, the attitude and/or behavior of all the employees in the organization thereby enhance workplace productivity.

Organizing Work. The university has an overall score for this domain at 3.35, which is highly productive. Specific score for each item included staff understanding their role in helping the organization achieve its goals (3.66); organization encourage staff to suggest ways to improve the products; services or the way they work (3.31); workplace regularly analyze work processes and work flows (3.26); and workplace recognize and reward people whose efforts support the firm's goals (3.26).

Networking and Collaboration. The total respondent score is highly productive (3.40). They are highly productive on organization has a good relationship with the community (3.57); organization has a good relationship with its students/clients/employees (3.55); organization connected with any local, regional or national government agencies or program (3.33); and 
organization well linked to other people and organizations in the industry or sector (3.32). But they are moderately productive on organization explored opportunities for working with or entering into joint ventures with others (3.20).

Successful initiatives necessitate collaboration between stakeholders across a range of organizational foci and expertise (Rozylowicz, Nita, Manolache, Ciocanea, \& Popescu, 2017). Under the principles of shared education to promote school improvement administrators are encouraged to sustain and do regular sharing learning between students and broader collaboration between teachers and school leaders from different schools (Duffy, \& Gallagher, 2017). In this case study, it stressed out that the partnership has an infrastructure which has both leader involvement and endorsement; teachers are planning together, co-teaching, creating new resources, and improving new practices; and the experience of shared learning and collaboration between staff appears to be standardizing operations.

Measuring What Matters. The total rating on this driver is highly productive (3.28). Specific ratings on highly productive items included organization able to collect the information it needs, to assess how well it is doing (3.39); the organization benchmark operation against industry best practice (3.29); organization measure or monitor customer satisfaction, employee morale and supplier feedback (3.28); and organization regularly measure a range of key performance measures/indicators that go beyond just financial performance (3.26). They are moderately productive on everyone to know what the organizationss key performance measures are (3.14).

In benchmarking and knowledge management practices, the vital question has ever been, "is there a better way to do what I do"? Castro, (2016) defined benchmarking concept as a process that permits an organization to increase its performance by comparing its products, services, and processes with others that are renowned as representing best practices. Ganushchak-Yefimenko, Shcherbak, \& Nifatova (2017) further stated that the goal is to replicate best foreign and national practices to improve services and operations, thereby increasing work productivity.

Analysis of efficiency among universities and their positioning in the global scientific and educational arena allowed connecting the level of successfulness of their strategic management to the level of manifestation of academic autonomy and with the growth of enrolment (Parakhina, 
Godina, Boris, \& Ushvitsky, (2017). The results of their research showed an option for solving the problems of strategic management in universities, employing the creation of updated working mechanisms of internal growth which matches to the external changes. These items include: (1) selection of the strategies which allow attaining exceptional competitive advantages, leadership in quality, cost, time, and image; (2) achievement of the mission and goals of universities by cascading it to the level of hierarchy within the system of harmonized indicators for particular list of functions, tasks, and measure indicators of university departments; (3) strengthening of marketing direction of strategic management within network, interuniversity, and international relations and alliances with organization (4) development and awareness of national and international strategies and through multifaceted collaboration in education, science, and innovations; and (5) emphasis on "blue ocean strategy" through formulation of own vision and mission and creation of new perspective markets.

Firms and academic community recognize the importance of creating an engaged customer. The study of Grewal, Roggeveen, Sisodia, \& Nordfält, (2017), proposes the use of consciousness to create a more engaging and meaningful customer experience based on the foundational philosophy of Conscious Capitalism with the four tenets of purpose and values, leadership and corporate culture, and stakeholder integration. This higher purpose and values are not necessarily about "doing good" for the world, as corporate social responsibility is, but rather exemplify a unifying vision for the university and its stakeholders. The leaders of the institution should mentor, monitor, develop, and inspire people and lead in generating a culture that is aligned with the purposes and values of the university. 
Table 3. Workplace Productivity of UB employees

\begin{tabular}{|c|c|c|c|c|c|c|c|c|c|c|c|}
\hline \multirow[t]{2}{*}{ Items } & \multicolumn{2}{|c|}{$\begin{array}{l}\text { Admin- } \\
\text { istrator } \\
(\mathrm{n} 1=27)\end{array}$} & \multicolumn{2}{|c|}{$\begin{array}{c}\text { Non- } \\
\text { teaching } \\
(\mathrm{n} 2=12)\end{array}$} & \multicolumn{2}{|c|}{$\begin{array}{l}\text { Support } \\
\text { services } \\
(\mathrm{n} 3=14)\end{array}$} & \multicolumn{2}{|c|}{$\begin{array}{l}\text { Teaching } \\
(\mathrm{n} 4=113)\end{array}$} & \multicolumn{3}{|c|}{ Total (166) } \\
\hline & WM & DV & WM & DV & WM & DV & WM & DV & WM & DV & $\mathrm{R}$ \\
\hline
\end{tabular}

A. Building Leadership and Management Capability

1. Does the workplace encourage leadership at every level of the organization?

$\begin{array}{lllllllllll}3.52 & \text { HP } & 3.67 & \text { HP } & 3.29 & \text { HP } & 3.27 & \text { HP } & 3.34 & \text { HP } & 1\end{array}$

2. Does the organization do succession planning for all jobs so there are clear career paths for staff?

$\begin{array}{llllllllllll}3.48 & \text { HP } & 3.42 & \text { HP } & 3.29 & \text { HP } & 3.09 & \text { MP } & 3.19 & \text { MP } & 5\end{array}$

3. Do the managers lead by example

$\begin{array}{lllllllllllll}\text { and create a positive and productive } & 3.37 & \mathrm{HP} & 3.42 & \mathrm{HP} & 3.29 & \mathrm{HP} & 3.16 & \mathrm{MP} & 3.22 & \mathrm{MP} & 4\end{array}$ work environment?

4. Does the organization invest in development and training for its managers?

$\begin{array}{lllllllllll}3.48 & \text { HP } & 3.58 & \text { HP } & 3.36 & \text { HP } & 3.12 & \text { MP } & 3.23 & \text { MP } & 3\end{array}$

5. Does the workplace support innovative thinking and make use of new ideas?

Composite Mean

3.48 HP 3.58 HP $3.29 \quad$ HP

3.21 MP 3.29 HP 2

B. Creating Productive Workplace Culture

1. Do people in the workplace treat each other well and value each others' ideas?

2. Do the staff share the same goals and values?

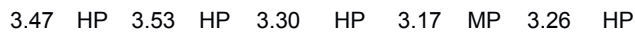

Does everyone in the organization get the chance to suggest how they could improve their part of the business?

4. Does the organization reward people for participating and suggesting good ideas?

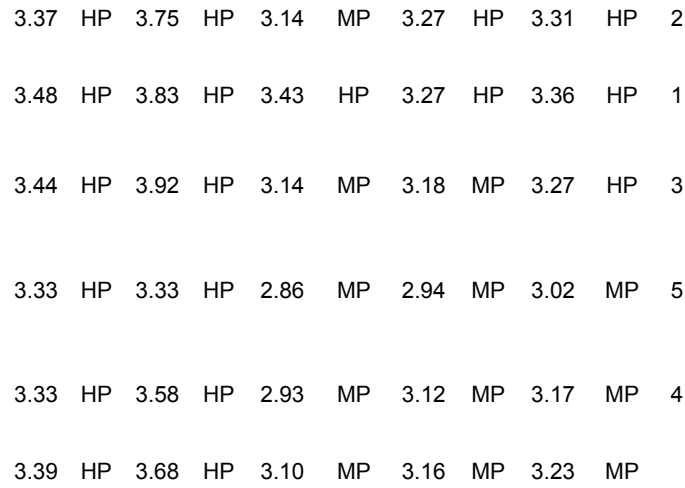

$\begin{array}{llllllllllll}3.33 & \mathrm{HP} & 3.58 & \mathrm{HP} & 2.93 & \mathrm{MP} & 3.12 & \mathrm{MP} & 3.17 & \mathrm{MP} & 4\end{array}$

$\begin{array}{llllllllll}3.39 & \mathrm{HP} & 3.68 & \mathrm{HP} & 3.10 & \mathrm{MP} & 3.16 & \mathrm{MP} & 3.23 & \mathrm{MP}\end{array}$

5. Does the workplace gather feedback from staff on the work environment and any ideas staff have for improving it?

Composite Mean

C. Encouraging Innovation and the Use of Technology

1. Does the organization invest in re$\begin{array}{lllllllllllll}\text { search and the development of new } & 3.70 & \text { HP } & 3.50 & \text { HP } & 3.50 & \text { HP } & 3.29 & \text { HP } & 3.39 & \text { HP } & 1\end{array}$ ideas, products or services?

2. Are staff asked about what new $\begin{array}{llllllllllll}\text { technology could be useful to intro- } & 3.41 & \mathrm{HP} & 3.50 & \mathrm{HP} & 3.21 & \mathrm{MP} & 3.13 & \mathrm{MP} & 3.21 & \mathrm{MP} & 2\end{array}$ duce into the organization?

3. Do staff receive training when new technology is introduced?

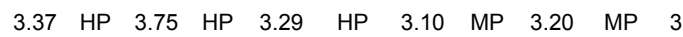

4. Is the workplace open to new ideas and doing things differently?

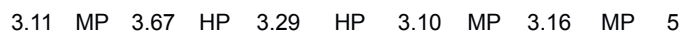

5. Are there opportunities for staff to suggest new ideas or processes?

$\begin{array}{lllllllllll}3.37 & H P & 3.75 & \text { HP } & 3.14 & \text { MP } & 3.10 & \text { MP } & 3.19 & \text { MP } & 4\end{array}$

$\begin{array}{llllllllll}3.39 & \text { HP } & 3.63 & \text { HP } & 3.29 & \text { HP } & 3.14 & \text { MP } & 3.23 & \text { MP }\end{array}$ 
D. Investing in People and Skills

1. Do staff receive the training they need to be effective?

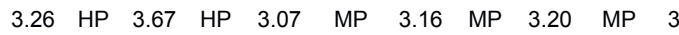

2. Are there opportunities in the workplace for all staff to have formal learning (e.g. Industry qualifications, $\begin{array}{llllllllllll}3.48 & H P & 3.75 & \text { HP } & 3.00 & \text { MP } & 3.11 & \text { MP } & 3.20 & \text { MP } & 3\end{array}$ job specific training)?

3. Are there opportunities in the workplace for experienced employees to support/coach/mentor less experienced staff?

4. Staff has good reading, writing, math and computing skills?

5. Do staff have personal career development discussions or plans?

Composite Mean

E. Organizing Work

1. As a staff, do you understand your role in helping the organization achieve its goals?

2. Does the workplace recognize and reward people whose efforts support the firm's goals?

3

$\begin{array}{llllllllllllll}.26 & \mathrm{HP} & 3.83 & \mathrm{HP} & 3.07 & \mathrm{MP} & 3.14 & \mathrm{MP} & 3.20 & \mathrm{MP} & 3\end{array}$

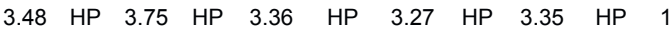

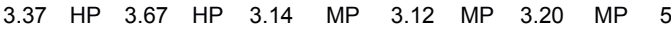

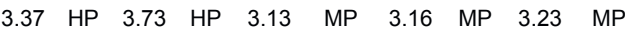

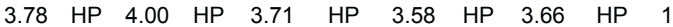

$\begin{array}{lllllllllll}3.44 & \mathrm{HP} & 3.50 & \mathrm{HP} & 2.86 & \mathrm{MP} & 3.23 & \mathrm{MP} & 3.25 & \mathrm{HP} & 4\end{array}$

3. Does the workplace regularly analyze work processes and work flows?

4. Does the organization encourage staff to suggest ways to improve the products, services or the way we work?

5. Do staff regularly share information between teams and work areas?

Composite Mean

$\begin{array}{llllllllll}3.37 & \text { HP } & 3.67 & \text { HP } & 3.07 & \text { MP } & 3.19 & \text { MP } & 3.25 & \text { MP } \\ 3.49 & \text { HP } & 3.70 & \text { HP } & 3.24 & \text { MP } & 3.29 & \text { MP } & 3.35 & \text { HP }\end{array}$

F. Networking and Collaboration

1. Is the organization well linked to other people and organizations in the industry or sector (ie local or national organizations)?

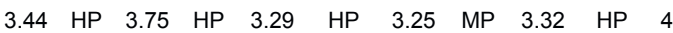

2. Has the organization explored op-

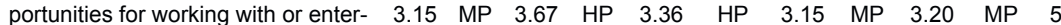
ing into joint ventures with others?

3. Is your organization connected with any local, regional or national government agencies or program (e.g. Trade \& Enterprise)?

4. The organization has a good relationship with the community?

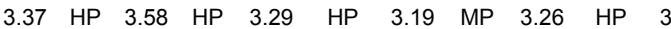

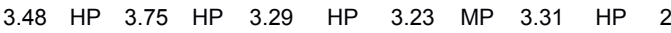

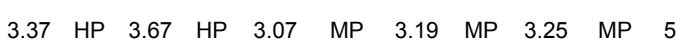

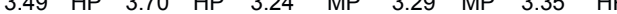

The organization has a good relationship with its students/clients/ employees?

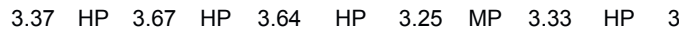

$\begin{array}{lllllllllll}3.74 & \text { HP } & 3.83 & \text { HP } & 3.79 & \text { HP } & 3.47 & \text { HP } & 3.57 & \text { HP } & 1\end{array}$

$\begin{array}{lllllllllll}3.70 & \text { HP } & 3.83 & \text { HP } & 3.71 & \text { HP } & 3.47 & \text { HP } & 3.55 & \text { HP } & 2\end{array}$

$\begin{array}{llllllllll}3.48 & \mathrm{HP} & 3.75 & \mathrm{HP} & 3.56 & \mathrm{HP} & 3.32 & \mathrm{HP} & 3.40 & \mathrm{HP}\end{array}$ 
G. Measuring What Matters

1. Is the organization able to collect the information it needs, to assess how 3.56 HP $\quad \begin{array}{llllllllll}3.50 & \mathrm{HP} & 3.57 & \mathrm{HP} & 3.31 & \mathrm{HP} & 3.39 & \mathrm{HP} & 1\end{array}$ well it is doing?

2. Does the organization regularly measure a range of key performance measures/indicators that go beyond just financial performance?

3. Does everyone know what the organization's key performance measures are?

4. Does the organization measure or monitor customer satisfaction, employee morale and supplier feedback?

5. Does the organization benchmark operation against industry best practice?

\begin{tabular}{lllllllllll}
\hline Composite Mean & 3.40 & HP & 3.47 & HP & 3.46 & HP & 3.19 & MP & 3.27 & HP \\
\hline Overall Composite Mean & 3.43 & HP & 3.64 & HP & 3.30 & HP & 3.20 & MP & 3.28 & HP \\
\hline
\end{tabular}

\section{Parameters:}

\begin{tabular}{llllll}
\multicolumn{2}{c}{ Range } & \multicolumn{2}{c}{ Interpretation } & \multicolumn{2}{c}{ Responses } \\
1.00 & 1.74 & UP & Unproductive & D & Disagree \\
1.75 & 2.49 & SP & Slightly Productive & SD & Slightly Disagree \\
2.50 & 3.24 & MP & Moderately Productive & SA & Slightly Agree \\
3.25 & 4.00 & HP & Highly Productive & A & Agree
\end{tabular}

\section{Analysis of Variance on the Different Dimensions on Workplace Productivity.}

The data as presented in Table $4 \mathrm{~A}, \mathrm{~B}$ and $\mathrm{C}$ obtained a computed value of $F=2.05236$ which is greater than the critical value of 0.79 at 33 by $2 \mathrm{df}$ and 0.05 level of significance hence showing a significant result. Since there is a significant result on the variance between respondents, multiple comparisons between means are computed using Scheffe's test. Results showed that there is a significant variance in creating productive workplace cultures and networking and collaboration. A significant result of variance was also noted on encouraging innovation and the use of technology and networking and collaboration as well as with investing in people and skills and networking and collaboration. All the rest of the drivers shows an insignificant result. Therefore, drivers that have a significant effect on workplace productivity in the university included encouraging innovation and the use of technology, networking, and collaboration and investing in people and skills. 
Table 4A. Analysis of Variance on the Different Drivers of Workplace Productivity

\begin{tabular}{cccccccc}
\hline $\begin{array}{c}\text { Respon- } \\
\text { dents }\end{array}$ & \multicolumn{2}{c}{$\mathrm{A}$} & $\mathrm{E}$ & \multicolumn{2}{c}{$\mathrm{F}$} & \multicolumn{3}{c}{$\mathrm{G}$} \\
& $\mathrm{X}_{1}$ & $\left(\mathrm{X}_{1}\right)^{2}$ & $\left(\mathrm{X}_{5}\right)^{2}$ & $\mathrm{X}_{6}$ & $\left(\mathrm{X}_{6}\right)^{2}$ & $\mathrm{X}_{7}$ & $\left(\mathrm{X}_{7}\right)^{2}$ \\
\hline $\mathrm{n}$ & 166 & & & 166 & & 166 & \\
Sum & 540.60 & 1817 & 1917 & 563.60 & 1960 & 542.80 & 1831 \\
Mean & 3.26 & & & 3.40 & & 3.27 & \\
SS & 1760.5323 & & & 1913.5239 & & 1774.8906 & \\
\hline
\end{tabular}

Table 4B. ANOVA Table

\begin{tabular}{cccccc}
\hline Sources of & df & Sum of & Mean & \multicolumn{2}{c}{ F-Value } \\
\hline Variation & & Squares & Squares & Computed & Tabular (0.05) \\
Between Groups & 6 & 4.24950 & 0.70825 & 2.05236 & 0.79 \\
Within Groups & 1155 & 398.5793 & 0.34509 & Result: Significant \\
Total & 1161 & 402.82878 & & Ho: Rejected \\
\hline
\end{tabular}

\section{Table 4C. Multiple Comparison Using Scheffe's Test}

\begin{tabular}{|c|c|c|c|c|c|c|c|c|c|c|}
\hline \multicolumn{3}{|c|}{$\begin{array}{c}\text { Between } \\
\text { Learning Areas }\end{array}$} & \multirow{2}{*}{$\begin{array}{c}\text { Mean1 } \\
3.26\end{array}$} & \multirow{2}{*}{$\begin{array}{c}\text { Mean2 } \\
3.23\end{array}$} & \multirow{2}{*}{$\begin{array}{c}D \\
0.03\end{array}$} & \multirow{2}{*}{$\begin{array}{l}\mathrm{n} 1 \\
166\end{array}$} & \multirow{2}{*}{$\begin{array}{l}\mathrm{n} 2 \\
166\end{array}$} & \multirow{2}{*}{$\begin{array}{c}F^{\prime} \\
0.2011\end{array}$} & \multirow{2}{*}{$\begin{array}{l}F^{*} \mathrm{~K}-1 \\
4.740\end{array}$} & \multirow{2}{*}{$\begin{array}{l}\text { Interpretation } \\
\text { Insignificant }\end{array}$} \\
\hline$A$ & vs & B & & & & & & & & \\
\hline A & vs & $C$ & 3.26 & 3.23 & 0.03 & 166 & 166 & 0.1540 & 4.740 & Insignificant \\
\hline A & vs & $D$ & 3.26 & 3.23 & 0.02 & 166 & 166 & 0.1397 & 4.740 & Insignificant \\
\hline A & vs & $E$ & 3.26 & 3.35 & -0.09 & 166 & 166 & 1.9118 & 4.740 & Insignificant \\
\hline A & vs & $\mathrm{F}$ & 3.26 & 3.40 & -0.14 & 166 & 166 & 4.6173 & 4.740 & Insignificant \\
\hline A & vs & G & 3.26 & 3.27 & -0.01 & 166 & 166 & 0.0422 & 4.740 & Insignificant \\
\hline B & vs & C & 3.23 & 3.23 & 0.00 & 166 & 166 & 0.0031 & 4.740 & Insignificant \\
\hline B & vs & D & 3.23 & 3.23 & 0.00 & 166 & 166 & 0.0056 & 4.740 & Insignificant \\
\hline B & vs & $E$ & 3.23 & 3.35 & -0.12 & 166 & 166 & 3.3531 & 4.740 & Insignificant \\
\hline B & vs & $\mathrm{F}$ & 3.23 & 3.40 & -0.17 & 166 & 166 & 6.7456 & 4.740 & Significant \\
\hline B & vs & G & 3.23 & 3.27 & -0.04 & 166 & 166 & 0.4277 & 4.740 & Insignificant \\
\hline C & vs & D & 3.23 & 3.23 & 0.00 & 166 & 166 & 0.0003 & 4.740 & Insignificant \\
\hline C & vs & $E$ & 3.23 & 3.35 & -0.11 & 166 & 166 & 3.1509 & 4.740 & Insignificant \\
\hline C & vs & $\mathrm{F}$ & 3.23 & 3.40 & -0.16 & 166 & 166 & 6.4575 & 4.740 & Significant \\
\hline C & vs & G & 3.23 & 3.27 & -0.04 & 166 & 166 & 0.3575 & 4.740 & Insignificant \\
\hline
\end{tabular}




\begin{tabular}{lllllllllll}
\hline D & vs & E & 3.23 & 3.35 & -0.11 & 166 & 166 & 3.0849 & 4.740 & Insignificant \\
D & vs & F & 3.23 & 3.40 & -0.16 & 166 & 166 & 6.3629 & 4.740 & Significant \\
D & vs & G & 3.23 & 3.27 & -0.04 & 166 & 166 & 0.3355 & 4.740 & Insignificant \\
E & vs & F & 3.35 & 3.40 & -0.05 & 166 & 166 & 0.5869 & 4.740 & Insignificant \\
E & vs & G & 3.35 & 3.27 & 0.08 & 166 & 166 & 1.3857 & 4.740 & Insignificant \\
F & vs & G & 3.40 & 3.27 & 0.13 & 166 & 166 & 3.7762 & 4.740 & Insignificant \\
\hline
\end{tabular}

Legend: $A=$ Building Leadership and Management Capability, $B=$ Creating Productive Workplace Cultures, $\mathrm{C}=$ Encouraging Innovation and the Use of Technology, $\mathrm{D}=$ Investing in People and Skills, E= Organizing Work, $F=$ Networking and Collaboration, $\mathrm{G}=$ Measuring What Matters

\section{CONCLUSIONS}

Employees' level of work engagement was assessed based on how productive they were at the workplace using the seven drivers in a workplace productivity tool. The UB employees are moderately productive on creating productive workplace cultures, creating a positive work environment motivates people and makes them feel valued and helps people commit to an organization and encourages people to 'go the extra mile.' A productive workplace culture is also one that values and shares people's insights and experience. These drivers can help the workplace to do things smarter and make the organization more innovative and productive over time.

Employees were also moderately productive in encouraging innovation and the use of technology. Innovation is the key to raising workplace productivity. Innovative and productive workplaces encourage all staff to think of ways to create new products and improve existing services, keep up with the play and use new technology, plan and organize themselves well and employ and value people with good skills and ideas. Creating new products or services or just doing things better are important ways of growing a business. The company's ability to innovate will depend on a range of factors - the skills of your employees, your workplace culture, how your work is organized and a shared vision of where the business is heading.

Lastly, the employees were moderately productive on the driver of investing in people and skills the more skills the staff have, the more innovative they can be. The more skills staff have, the more they can 
contribute. Skilled staff are more capable with new technology, work more quickly with fewer mistakes, require less supervision, and accept more responsibility and are better communicators. An organization's commitment to training is essential for raising skills and creating a highlyskilled workforce. Effective training leads to higher skills and wages and lower staff turnover.

Workplace Productive Snapshot Tool defines moderately productive as those needing continuing feedback, monitoring, and evaluation to keep up with individual, organizational, and environmental challenges.

\section{RECOMMENDATIONS}

Based on the salient findings made and derived from the extensive study, the following recommendations are put forward for each drivers necessitating continuous feedback, monitoring, and evaluation:

1. With regards to building leadership and management capability, the institution should do succession planning for all jobs, so there are clear career paths for all employees. Managers and supervisory levels should have regular, relevant, and sustainable training and development program to lead effectively and create a positive and productive work environment. And cultivate leadership skills at every rank of the organization.

2. To create a productive workplace culture, an excellent and systematic scheme of recognizing for staff who are participating and contributing to the achievement of the institutional vision, mission, goals and strategic targets should be in place across all positions and departments. At the same time, the university should gather feedback from staff on the work environment, and any ideas staff have for improving services and processes. And institute activities that can motivate the human capital to pursue greater heights.

3. In the area of encouraging innovation and the use of technology, staff should ask about what new technology could be useful to introduce, receive training with modern technology, and the workplace should be open to new ideas and in doing things differently.

4. To create a human resource management plan in determining the learning and development ( $L \& D$ ) needs that will enable 
the employees to improve performance and achieve higher workplace productivity continually. Such will be done by employing appropriate techniques in investing in people and skills, Provide for an avenue for the experienced employees to support/coach/ mentor less experienced staff. Regularly engage employees in research and development initiatives and projects. Require employee training needs assessment when new technology is available. The administration should be open to innovation and doing things differently and giving workers the platform to provide new ideas or processes.

5. In organizing work, staff must regularly share information between teams and work areas. A well-organized workplace can obtain the best out of its staff.

6. Create benchmark performance management systems in the institution to gather best practices among exemplary institutions. Such shall provide an avenue to engage in joint ventures and collaboration to open an avenue in accessing new resources and improve services, systems, and processes.

7. To provide the correct information needed to find out how the business fare. It is essential that key performance measures and indicators are cascaded down to the lowest position in the institution to connect with the same level of institutional successfulness.

\section{REFERENCES CITED}

Ahmed, A. A., Abu-Naser, S. S., El Talla, S. A., \& Al Shobaki, M. J. (2018). The Impact of Information Technology Used on the Nature of Administrators Work at Al-Azhar University in Gaza. Retrieved from https://bit. ly/32vM9XG. (Accessed last July 18, 2019).

Alfes, K., Shantz, A. D., Truss, C., \& Soane, E. C. (2013). The link between perceived human resource management practices, engagement and employee behaviour: a moderated mediation model. The international journal of human resource management, 24(2), 330-351. Retrieved from https://bit.ly/2Gdq2vG. (Accessed last August 7, 2019).

Bakker, A. B. (2011). An evidence-based model of work engagement. Current Directions in Psychological Science, 20(4), 265-269. Retrieved from http:// 
goo.gl/FgXa78. (Accessed last August 7, 2019).

Bakker, A. B., \& Leiter, M. P. (Eds.). (2010). Work engagement: A handbook of essential theory and research. Psychology Press. Retrieved from https://goo.gl/vg1Ycf. (Accessed last August 7, 2019.

Bakker, A. B. (2017). Strategic and proactive approaches to work engagement. Organizational Dynamics, 46(2), 67-75. Retrieved from https://bit.ly/2JBT1v4. (Accessed last July 18, 2019).

Bellou, V. (2010). Organizational culture as a predictor of job satisfaction: the role of gender and age. Career Development International, 15(1), 4-19. Retrieved from https://bit.ly/2XZrMil. (Accessed last July 18, 2019).

Castro, V. F. D. (2016). A framework to identify, measure and benchmark operations management best practices. Retrieved from https://bit. ly/2JFjKHu. (Accessed last July 19, 2019).

Dartey-Baah, K., \& Amoako, G. K. (2011). Application of Frederick Herzberg's Two-Factor theory in assessing and understanding employee motivation at work: a Ghanaian Perspective. European Journal of Business and Management, 3(9), 1-8. Retrieved from http://goo.gl/wRPcPw. (Accessed last August 13, 2015).

Duffy, G., \& Gallagher, T. (2017). Shared Education in contested spaces: How collaborative networks improve communities and schools. Journal of Educational Change, 18(1), 107-134. Retrieved from https://bit. ly/2XTLSuh. (Accessed last July 18, 2019).

Ganushchak-Yefimenko, L., Shcherbak, V., \& Nifatova, O. (2017). Managing a project of competitive-integrative benchmarking of higher educational institutions. Eastern-European journal of enterprise technologies. Retrieved from https://bit.ly/2Srvos7. (Accessed last July 19, 2019).

Grewal, D., Roggeveen, A. L., Sisodia, R., \& Nordfält, J. (2017).

Enhancing customer engagement through consciousness. Journal of Retailing, 93(1), 55-64. Retrieved from https://bit.ly/2O4IVHp. (Accessed last July 19, 2019). 
Ibrahim, R., Boerhannoeddin, A., \& Bakare, K. K. (2017). The effect of soft skills and training methodology on employee performance. European Journal of Training and Development, 41(4), 388-406. Retrieved from https://bit.ly/2XM6RUo. (Accessed last July 18, 2019).

Knight, C., \& Haslam, S. A. (2010). The relative merits of lean, enriched, and empowered offices: an experimental examination of the impact of workspace management strategies on well-being and productivity. Journal of Experimental Psychology: Applied, 16(2), 158. Retrieved from http://goo.gl/0ZBa9W. (Accessed last September 1, 2019).

Kompaso, S. M., \& Sridevi, M. S. (2010). Employee engagement: The key to improving performance. International Journal of Business and Management, 5(12), p89. Retrieved from http://goo.gl/rrWe1l. (Accessed last August 13, 2019).

Lottrup, L., Stigsdotter, U. K., Meilby, H., \& Claudi, A. G. (2015). The workplace window view: a determinant of office workers' work ability and job satisfaction. Landscape Research, 40(1), 57-75. Retrieved from https:// bit.ly/2SmrkJB. Accessed last August 7, 2019.

Masa'deh, R. E., Almajali, D. A., Alrowwad, A. A., \& Obeidat, B. (2019). THE ROLE OF KNOWLEDGE MANAGEMENT INFRASTRUCTURE IN ENHANCING JOB SATISFACTION: A DEVELOPING COUNTRY PERSPECTIVE. Interdisciplinary Journal of Information, Knowledge \& Management, 14. Retrieved from https://bit.ly/2M18nv3. Accessed last July 18, 2019.

Neves, P., \& Eisenberger, R. (2014). Perceived organizational support and risk taking. Journal of Managerial Psychology, 29(2), 187-205. http://goo. gl/WUKHAk. (Accessed last September 14, 2019).

Papay, J. P., \& Kraft, M. A. (2015). Productivity returns to experience in the teacher labor market: Methodological challenges and new evidence on long-term career improvement. Journal of Public Economics. Retrieved from http://goo.gl/4wQzXs. (Accessed last August 26, 2019).

Parakhina, V., Godina, O., Boris, O., \&Ushvitsky, L.(2017).Strategicmanagement in universities as a factor of their global competitiveness. International 
Journal of Educational Management, 31(1), 62-75. Retrieved from https:// bit.ly/2YckJXn. (Accessed last July 19, 2019).

Rozylowicz, L., Nita, A., Manolache, S., Ciocanea, C. M., \& Popescu, V. D. (2017). Recipe for success: A network perspective of partnership in nature conservation. Journal for Nature Conservation, 38, 21-29. Retreived from https://bit.ly/2JRvaXv. Accessed last July 18, 2019.

Schaufeli, W., \&Salanova, M. (2011). Work engagement: On how to better catch a slippery concept. European Journal of Work and Organizational Psychology, 20(1), 39-46.Retrieved from https://goo.gl/q05Pt6, (accessed last August 7, 2019).

Stello, C. M. (2011). Herzberg's two-factor theory of job satisfaction: An integrative literature review. In Unpublished paper presented at The 2011 Student Research Conference: Exploring Opportunities in Research, Policy, and Practice, University of Minnesota Department of Organizational Leadership, Policy and Development, Minneapolis, MN. Retrieved from http://goo.gl/DIAAnw. (Accessed last August 13, 2015).

Suojanen, I. (2012). Work for your happiness-Theoretical and empirical study defining and measuring happiness at work. Retrieved from http:// goo.gl/BMw1wc. (Accessed last August 29, 2019).

Tan, T. H., \& Waheed, A. (2011). Herzberg's motivation-hygiene theory and job satisfaction in the Malaysian retail sector: The mediating effect of love of money. Retrieved from http://goo.gl/0VQIEQ. (Accessed last August 13, 2019).

Van der Voordt, T., \& Riratanaphong, C. (2014). Measuring the added value of workplace change. Comparison between Theory and Practice.

Retrieved from http://goo.gl/AEWKta. (Accessed last August 26, 2019). 